\title{
Density-dependent increase in superpredation linked to food limitation in a recovering population of northern goshawks, Accipiter gentilis
}

S.R. Hoy a, ${ }^{\text {ab }}$ S.J. Petty ${ }^{\text {a }}$, A. Millon ${ }^{\text {c}}$, D.P. Whitfield ${ }^{\mathrm{d}}$, M. Marquiss ${ }^{\mathrm{a}}$, D.I.K. Anderson ${ }^{\mathrm{e}}$, M. Davison ${ }^{\mathrm{f}}$, \& X. Lambin ${ }^{\mathrm{a}}$

${ }^{\text {a }}$ School of Biological Sciences, University of Aberdeen, Aberdeen AB24 2TZ, UK

${ }^{\mathrm{b}}$ Michigan Technological University, Houghton, Michigan 49931

c Aix Marseille Universite, Universite Avignon, CNRS, IRD, IMBE, Technopôle ArboisMéditerranée, 13545 Aix-en-Provence, France

${ }^{\mathrm{d}}$ Natural Research Limited, Banchory, AB31 4BY, UK

${ }^{\mathrm{e}}$ Forest Enterprise Scotland, Aberfoyle, Stirling, FK8 3UX

${ }^{\mathrm{f}}$ Forestry Commission, Bellingham, NE48 2HP, UK

* Corresponding author: x.lambin@abdn.ac.uk 
A better understanding of the mechanisms driving superpredation, the killing of smaller mesopredators by larger apex predators, is important because of the crucial role superpredation can play in structuring communities and because it often involves species of conservation concern. Here we document how the extent of superpredation changed over time, and assessed the impact of such temporal variation on local mesopredator populations using 40 years of dietary data collected from a recovering population of northern goshawks (Accipiter gentilis), an archetypical avian superpredator. We then assessed which mechanisms were driving variation in superpredation, e.g., was it opportunistic, a response to food becoming limited (due to declines in preferred prey) or to reduce competition. Raptors comprised $8 \%$ of goshawk diet on average in years when goshawk abundance was high, which is higher than reported elsewhere. Additionally, there was a per capita increase in superpredation as goshawks recovered, with the proportion of goshawk diet comprising raptors increasing from $2 \%$ to $8 \%$ as the number of goshawk home-ranges increased from $\leq 14$ to $\geq 25$. This increase in superpredation coincided with a population decline in the most commonly killed mesopredator, the Eurasian kestrel (Falco tinnunculus), which may represent the reversal of the “mesopredator release” process (i.e., mesopredator suppression) which occurred after goshawks and other large raptors declined or were extirpated. Food limitation was the most likely driver of superpredation in this system given: 1) the substantial decline of two main prey groups in goshawk diet, the increase in diet diversity and decrease in goshawk reproductive success are all consistent with the goshawk population becoming food-limited; 2) it's unlikely to be purely opportunistic as the increase in superpredation did not reflect changes in the availability of mesopredator species; and 3) the majority of mesopredators killed by goshawks do not compete with goshawks for food or nest sites. 
42 Understanding the mechanisms driving variation in superpredation, the killing of smaller mesopredators by larger apex predators, is an important issue in ecology. This is partly because superpredation can directly impact mesopredator population dynamics which may then cascade to affect lower trophic levels (Paine 1980), but also because many of the superpredator and mesopredator species involved are of conservation concern (Palomares and Caro 1999, Caro and Stoner 2003, Ripple and Beschta 2004, Ritchie and Johnson 2009). However, despite this, and the crucial role superpredation can play in structuring communities, it is still not clear what mechanism (or combination of mechanisms) drives one predator to kill another.

Optimal foraging theory suggests that predators should attempt to kill prey when the energy gained outweighs the energetic cost and potential risk of injury involved (Berger-Tal et al. 2009). However, mesopredators are unlikely to represent a profitable prey source, even when they fall within the preferred size range of the superpredator, because their densities are often relatively low compared to that of other prey species. Furthermore, the risk of injury associated with attacking mesopredators is presumably higher than for other prey types, because mesopredators have evolved to kill other species (Lourenço et al. 2011a). Consequently, several alternative (but not mutually exclusive) hypotheses have been put forward to explain superpredation. The competitor-removal hypothesis suggests that superpredators kill mesopredators to free up shared resources (Serrano 2000). This leads to the prediction that superpredation will largely involve mesopredator species which compete with the superpredator for food or other resources, such as nest sites (e.g. intraguild predation). In contrast, the predator-removal hypothesis suggests that superpredation is a pre-emptive tactic 
2011b). Under this scenario, the mesopredator species expected to be killed the most frequently are those which pose a threat to the superpredator or their offspring.

Alternatively, rather than being a response to the presence of other predators, the foodlimitation hypothesis, also known as the food-stress hypothesis, suggests that mesopredators are killed to make up the shortfall in the superpredators diet when preferred prey species decline (Polis et al. 1989, Serrano 2000, Rutz and Bijlsma 2006, Lourenço et al. 2011a, b). Food limitation may also occur if there is an increase in the number of individuals (conspecifics or other species) exploiting preferred prey species, particularly if increasing predator densities elicit anti-predator behaviours in their prey (such as spatial or temporal avoidance of risky areas) which make prey more difficult to find and/or catch. Many populations of large predator species are currently increasing in abundance and recovering their former ranges across both North America and Europe (Maehr et al. 2001, Deinet et al. 2013, Chapron et al. 2014). Consequently, if superpredation is a response to density dependent food limitation, then the extent of superpredation occurring might be expected to increase during the recolonisation process, even if mesopredators are not a preferred prey species. However, whether such a per capita increase in superpredation has actually occurred or whether it coincides with or follows the colonisation process is as yet unknown.

Here we evaluate support for the food-limitation hypothesis, and other proposed determinants of superpredation in a recovering population of northern goshawks (Accipiter gentilis), using data collected between 1973 and 2014, over a 964km² area of Kielder Forest, United Kingdom $\left(55^{\circ} 13^{\prime} \mathrm{N}, 2^{\circ} 33^{\prime} \mathrm{W}\right)$. The northern goshawk (hereafter goshawk) is an archetypical avian superpredator known to prey upon a large diversity of both avian and mammalian prey, including other raptors (Rutz et al. 2006, Sergio and Hiraldo 2008, Lourenço et al. 2011a). 
90 Goshawks are the apex predator in this study system as Kielder Forest lacks other predator species known to prey on goshawks, such as Eurasian eagle owls (Bubo bubo) (Chakarov and Krüger 2010).

Goshawks were extirpated from the UK in the late $19^{\text {th }}$ century. However, scattered populations were subsequently re-established in the 1960s and 70s after birds escaped or were released by falconers (Marquiss and Newton 1982, Petty and Anderson 1995, Petty 1996). In Kielder Forest the goshawk population recovered rapidly after the first recorded breeding attempt in 1973, and 25-33 goshawk home-ranges are now occupied (see Appendix S1; Petty \& Anderson 1995). Such a large increase in goshawk abundance, was presumably concomitant with an increase in intraspecific competition for food and nest sites. However, goshawks may also have become food-limited because of a long-term decline in the abundance of red grouse (Lagopus lagopus) and a substantial decline of feral pigeon (Columba livia) in recent years in England (Robinson et al. 2015), as both species are important prey for goshawks in our study area (Petty et al. 2003a). The term feral pigeon includes both racing and homing pigeons.

The first aim of this study was to quantify the extent of superpredation and then to test the prediction that there has been a per capita increase in superpredation during the colonisation process by examining goshawk dietary data. Our second aim was to determine whether superpredation was impacting local populations of the most commonly preyed upon mesopredator species, for which local population trends are well characterised. We then assessed whether the goshawk population had become food-limited as the population recovered. It is difficult to directly assess food limitation for generalist predators, such as goshawks, without comprehensive prey abundance surveys (Rutz and Bijlsma 2006). Consequently, we examined two different lines of evidence to proximately assess food 
limitation. First, we examined temporal variation in goshawk diet to determine whether there had been any decline in the contribution of certain prey species/groups known to be important for goshawks. We then examined changes in the reproductive success of the goshawk population, because reproductive success is closely associated with food availability in goshawks and other raptor species (Newton 1979, 1998, Rutz and Bijlsma 2006, Millon et al. 2008). Lastly, we evaluated evidence supporting the alternative hypotheses of superpredation by examining which mesopredator species were being killed by goshawks (e.g. were they known to compete with goshawks for food or nesting sites).

\section{METHODS}

Kielder Forest is situated in Northumberland, in the north of England, adjacent to the border with Scotland. For a map of the study area see (Petty et al. 2003b). Each year active goshawk home-ranges were located by searching suitable nesting habitat within the forest (between the end of February and end of the breeding season). The locations of active nests were recorded and these sites were then visited at least four times to establish whether a breeding attempt took place, to record the number of chicks that fledged and collect dietary data.

\section{Quantifying superpredation}

To quantify superpredation and to determine whether there had been a per capita increase in superpredation as the goshawk population expanded, we used goshawk dietary data. Specifically, we quantified the proportion of goshawk diet comprised of other raptor species each year. Here we use the term raptor to refer to all diurnal and nocturnal birds of prey.

137 Goshawk diet was characterised by searching for the remains of prey (feathers, bones and fur) in the area surrounding active nest sites during nest visits between March-August, 1975-2014 (except between1999-2001), in the same way as described in Petty et al.(2003). When possible, 
at the end of the breeding season the top layer of nesting material was removed from active nests and searched for additional prey remains. Prey remains were removed or buried to avoid double counting in subsequent searches. We were able to identify 7763 prey items to species level by comparison with reference collections. It was not always possible to differentiate carrion crow (Corvus corone) from rook (C. frugilegus) remains. Therefore crow/rook refers to the abundance of both species in the diet, although rooks were scarce in the study area. We identified and quantified the minimum number of individuals of medium to large prey species by counting skeletal remains, whereas small avian prey (less than 100g) were identified and in terms of biomass.

Once the proportion of goshawk diet comprising raptors had been calculated for each nest ranges above $355 \mathrm{~m}$ were generally surrounded by open moorland habitat, whereas homesite/year, we examined how it varied in relation to the number of occupied goshawk homeranges (measured as a continuous variable) using generalised linear mixed effect models (GLMM) with a binomial error structure fitted using the Ime4 package (Bates et al. 2015). Goshawk diet has previously been shown to change with altitude, presumably reflecting changes in abundance and diversity of prey species at different altitudes (Marquiss and Newton 1982, Toyne 1998). Consequently, we also examined whether the contribution of raptors to diet varied with the altitude of the goshawks nest site. Goshawk home-ranges were grouped into three altitudinal bands as follows: low, if the nest site was $225 \mathrm{~m}$ or below, medium if between $226-354 \mathrm{~m}$, and high if 355m or above. We used these cut-offs because goshawk homeranges below $225 \mathrm{~m}$ were surrounded by forest, pasture and water (streams, rivers and a large 
reservoir). The identity of home-ranges and year were both fitted as random effects to account for variation in diet between years and between home-ranges. Model selection was based on Akaike’s information criterion corrected for small sample size (AICc) and AICc weights ( $W$; Burnham and Anderson 2002). The best performing model will have a $\triangle \mathrm{AIC}$ of zero, because $\triangle \mathrm{AICc}$ is the AICc for the model of interest minus the smallest AICc for the set of models being considered. Models are generally considered inferior if they have a $\Delta$ AICc $>2$ units. AICc weights $(w)$ are an estimate of the relative likelihood of a particular model for the set of models being considered. Model assumptions were validated by visually inspecting residual plots; but they did not reveal any obvious nonlinear relationships, unless otherwise mentioned. Correlograms (with a lag distance up to $10 \mathrm{~km}$ ) were used to check for spatial-autocorrelation autocorrelation in this, nor any other analyses of goshawk diet.

\section{Impact on local mesopredator populations}

To assess the impact of changes in goshawk predation on local populations of the three most frequently preyed upon raptor species Eurasian kestrels (Falco tinnunculus), tawny owls (Strix aluco) and Eurasian sparrowhawks (Accipiter nisus; Petty et al. 2003), we first examined whether the proportion of goshawk diet comprising these three raptor species changed with goshawk abundance (measured as a continuous variable) using the same GLMM approach described above. We then used dietary data to estimate the minimum number of each mesopredator species killed each year by goshawks when $\leq 14,15-24$ and $25+$ goshawk homeranges were occupied (for methods see Appendix 2). We used these three goshawk abundance categories to keep broadly similar sample sizes despite large variation in the number of prey remains recovered each year (range 10 -678). Temporal variation in predation rates on kestrel, 
of these species. Annual counts of territorial kestrel pairs in and around the forest have been recorded since 1975 as part of a larger study on merlins (Falco columbarius; Newton, Meek \& Little 1986; Little, Davison \& Jardine 1995). Breeding tawny owls have been monitored continuously in a subsection of the forest since 1979 (Petty 1992, Petty et al. 1994, Hoy et al. 2015). The number of occupied sparrowhawk territories in a subsection of the study area has been recorded since 1974 (Petty 1979; Petty et al. 1995).

\section{Assessing food limitation}

\section{Declines in important prey}

To indirectly infer if the goshawk population had become food-limited we assessed whether there had been any decline in the contribution of important prey species/groups in the diet. We first examined how the dominance of main prey species in the diet changed as the goshawk population expanded. This was done by ranking species from most to least important, firstly in terms of their frequency contribution to diet and then in terms of their biomass when the number of occupied goshawk home-ranges was $\leq 14,15-24$ and $25+$. A full list of species killed by goshawk and their mean body mass values used in biomass calculations can be found in Appendix 3. Certain taxonomic groups are known to be important to goshawk diet. For example, Columbiformes are an important prey for goshawks across most of Europe, comprising up to $69 \%$ of all prey items (reviewed in Rutz et al. 2006). Whereas, Tetraonidae comprised almost $80 \%$ of goshawk diet in some years at northerly latitudes, and in southern Europe Lagomorphs were an important prey source (reviewed in Kenward 2006). We therefore categorised prey into taxonomic groups as follows: raptors, pigeons (Columbiformes), corvids (Corvidae), game birds (Tetraonidae and Phasianidae) mammals (mainly Lagomorpha, and Sciuridae), and 'other'. This 'other' group largely consists of passerines but also includes other prey species, which are only occasionally taken. We then estimated both the frequency and 
biomass contribution of these groups to goshawk diet and examined how the frequency contribution varied in relation to goshawk abundance (measured as a continuous variable) using the same GLMM approach. We were unable to assess whether variation in the proportion of goshawk diet comprised of these different prey species/groups were related to changes in the abundance of these prey species/groups as local population trends were not available. Lastly, because diet diversity had generally been observed to increase in other raptor populations as they became food-limited (Rutz and Bijlsma 2006, Lourenço et al. 2011a), we also examined how prey diversity changed with goshawk abundance using estimates of the Shannon-Wiener diversity index when $\leq 14 ; 15-24 ; 25+$ goshawk home-ranges were occupied.

\section{Goshawk reproductive success}

We also indirectly assessed whether the goshawk population had become food-limited by examining how goshawk reproductive success varied in relation to the number of occupied home-ranges (measured as a continuous variable). In this analysis, we used two different measures of reproductive success: the average number of chicks fledged per successful breeding attempt and the proportion of breeding attempts which failed. We did not analysed variation in goshawk reproductive success prior to 1977 because goshawks did not reproduce successfully until a few years after the first home-ranges became established. Because the relationship between goshawk abundance and the number of chicks fledged per successful breeding attempt appeared to be non-linear we used generalised additive models (GAM) to characterise this relationship, fitted using the mgcv package (Wood 2015). In contrast, the relationship between the proportion of failed goshawk breeding attempts and goshawk abundance could be adequately characterised by generalised linear models (GLM) with a binomial error structure. All analyses were carried out in R version 3.0.3 (R Core Development Team 2015). Descriptive statistics are presented as the mean \pm 1SD. 


\section{RESULTS}

\section{Superpredation increased during the colonisation process}

243 Overall, raptors comprised 6\% of all identifiable prey killed by goshawks $(N=7763)$ and represented $4 \%$ of goshawk prey in terms of biomass (Appendix 4). There was a per capita increase in superpredation as goshawks recovered, with the proportion of goshawk diet comprised of raptors increasing from $2 \%$ to $8 \%$ as the number of goshawk home-ranges increased from $\leq 14$ to $\geq 25$. However, the proportion of raptors in goshawk diet was best modelled by an interaction between goshawk abundance and the altitude of the goshawk homerange (Table 1). The contribution of raptors to goshawk diet increased with goshawk abundance in home-ranges at the two lower elevations bands ( $\leq 225 \mathrm{~m}$ and $226-354 \mathrm{~m})$. However, there was no significant change in the proportion of raptors in the diet at higher altitudes (e.g., above $350 \mathrm{~m}$ ), where the contribution of raptors to goshawk diet was highest (Fig. 1a).

\section{Impact on local mesopredator populations}

255

Kestrels and tawny owls were both ranked within the 10 most important prey species, both in terms of their frequency and biomass contribution to diet (Table 2). Kestrels were the most commonly predated raptor species, representing almost half (49\%) of all raptors killed by goshawks ( $\mathrm{N}=465$; Appendix 5). However, this proportion declined from $55 \%$ to $39 \%$ as the number of occupied goshawk home-ranges increased from $<15$ to $>24$ (Appendix 5). Kestrels contributed most to goshawk diet in high altitude home-ranges (Fig. 2a). The number of kestrels estimated to be killed each year by the goshawk population initially increased with goshawk abundance, from 14 [11-18 95\% CI] when fewer than 15 goshawk home-ranges were occupied to 223 [197-248 95\% CI] when 15-24 home-ranges were occupied. However, it then declined to 176 [154-198 95\% CI] when more than 24 goshawk home-ranges were occupied 
(Table 3). At the same time, there has been a substantial decline in the number of kestrel pairs recorded breeding in the study site. For example, there were 29 breeding pairs in 1981 compared to only five pairs in 2014.

268

Tawny owls then sparrowhawks were the next most commonly preyed upon raptor species, representing 23\% and 10\% respectively of all raptors killed by goshawks (Appendix 5). The contribution of both tawny owls and sparrowhawks in goshawk diet increased as the number of goshawk home-ranges increased; however, there was no evidence to suggest that it varied with altitude (Table 1; Fig.2b-c). The rank order importance of tawny owls to goshawk diet also increased from 9 to 7 as the number of occupied goshawk home-ranges increased from $15-24$ to $\geq 25$ (Table 2). Our estimates suggested there was huge increase in the number of tawny owls killed by goshawks each year, from an average of 5 [3-8 95\% CI] to 159 owls [141$17695 \% \mathrm{CI}$ ] as the number of occupied goshawk home-ranges increased from $<15$ to $>24$ (Table 3). The number of sparrowhawks killed by goshawks was also estimated to increase, from 1 [1-2 95\% CI] to 53 [44-61 95\% CI] as the number of occupied goshawk home-ranges increased from $<15$ to $>24$ (Table 3). Despite the estimated increase in predation on both tawny owls and sparrowhawks, there was no evidence to suggest that local populations had declined. That is, there was little interannual variation in the number of occupied tawny owl territories, which averaged $56 \pm 4.07$ between 1985-2014 (Hoy et al. 2015), and sparrowhawks were known to occupy 7-14 home-ranges between 1974-1979 (Petty 1979) and 7-16 home-ranges between 2002-2014 (unpublished data).

\section{Assessing food limitation}


289 Almost half (48\%) of all identifiable prey items were pigeons (Appendix 4). Wood pigeon 290 (Columba palumbus) then feral pigeon were the two commonest prey species, irrespective of 291 the number of goshawk home-ranges occupied (Table 2). The proportion of pigeons in 292 goshawk diet declined over the study period as goshawk abundance increased, irrespective of 293 home-range altitude (Fig. 1b; Table 4). For example, the biomass contribution of pigeons to diet declined from $52 \%$ to $40 \%$ as the number of home-ranges increased from $<15$ to $>24$. This decline in pigeon in goshawk diet appeared to be driven by a decrease in feral rather than wood pigeons. The contribution of pigeons to goshawk diet was lowest in higher altitude homeranges, where moorland habitat predominated (Fig 1b; Table 4).

Crow/rook, red grouse and rabbit consistently ranked within the top-5 most important prey 300 species, both in terms of biomass and frequency contribution to diet, irrespective of the number of goshawk home-ranges occupied (Table 2). The proportion of corvids and mammals in the diet increased with goshawk abundance (Fig 2c-d). For example, corvids and mammals comprised $11 \%$ and $4 \%$ respectively of diet (in terms of frequency) when $<15$ home-ranges were occupied, but $19 \%$ and $8 \%$ of diet respectively when $>24$ home-ranges were occupied (Appendix 4). In contrast, the contribution of game birds (including red grouse) declined as goshawk abundance increased, in all three altitudinal categories (Table 4; Fig. 2e). Although the dietary contribution of corvids and mammals did not vary with altitude, the proportion of game birds (especially red grouse) was noticeably higher for high altitude home-ranges (e.g., above 350m; where moorland habitat is more common). Goshawk diet also became more diverse as goshawk abundance increased, with the Shannon-Wiener diversity index increasing by $24 \%$ from 2.1 to 2.6 when the number of occupied goshawk territories increased from being $<15$ to $>24$. 
315 Overall the reproductive success of goshawks declined as the number of occupied home-ranges increased. This decline appeared to be driven by both a decline in the average number of chicks fledging per successful breeding attempt and an increase in the number of nesting attempts failing (Fig. 3). The number of chicks fledging per successful breeding attempt decreased from an average of $2.90 \pm 0.24$ chicks to $2.29 \pm 0.36$ chicks as the number of occupied goshawk home-ranges increased from $<15$ to $>24$ (Fig. 3a). The proportion of successful breeding attempts declined from an average of $0.81 \pm 0.18$ to $0.58 \pm 0.14$ when the number of occupied home-ranges increased from $<15$ to $>24$ (Fig. 3b).

\section{DISCUSSION}

\section{Superpredation has increased during the recolonization process}

The amount of superpredation in our study site, particularly in recent years, is noticeably higher than recorded elsewhere. For example, raptors comprised up to 8\% of goshawk diet in Kielder Forest when goshawk abundance was high (Appendix 4) which is higher than the average of 2\% estimated in a review of goshawk diet in Europe (Rutz et al. 2006, Lourenço et al. 2011a). Whilst many other studies provide a snapshot indication of the frequency of superpredation in a given system, relatively few have documented temporal variation in the frequency of superpredators killing other predators (but see Serrano 2000, Rutz and Bijlsma 2006), particularly in a recovering superpredator population. That there was a per capita increase in superpredation as the goshawk population recovered (Fig. 1a) has potentially important implications for conservation and management, because similar increases in superpredation may be expected in other superpredator populations currently recolonising former ranges in both North America and Europe (Maehr et al. 2001, Deinet et al. 2013, Chapron et al. 2014). For example, if increases in superpredation negatively affect the dynamics of mesopredator 
species which are also of conservation concern it could lead to management conundrums for conservation projects aimed at restoring apex predator populations. However, it is important to note that when apex predator populations were reduced or extirpated, many previously suppressed mesopredator populations increase dramatically (Soulé et al. 1988, Crooks and Soulé 1999, Ritchie and Johnson 2009). Consequently, any declines in mesopredator populations which accompany the restoration of large predators may represent the reversal of this “mesopredator release" process (i.e., mesopredator suppression), rather than a shift to a new state.

\section{Impact on local mesopredator populations}

It's important to note that our calculations of how many kestrels, tawny owls and sparrowhawks were killed by goshawks each year is not only likely to include breeding birds (i.e. the ones on which local population counts were based) but also non-breeders (e.g., "floaters”), individuals migrating through the study site (in the case of kestrels) and immigrants from neighbouring populations. Nevertheless, the large increase in the number of kestrels being killed each year (from an estimated 14 to 176; Table 3) coincided with a decline in the local kestrel population, which is consistent with an increase in goshawk predation having a negative impact upon the local kestrel population. However, the decline in kestrels could also be partly related to other factors, such as habitat changes or a decline in the amplitude of field vole (Microtus agrestis) population cycles in the study area (Cornulier et al. 2013), as they are the main prey for kestrels in our study site. Nevertheless, our results suggest that goshawks were killing a progressively greater proportion of a declining kestrel population, which may have contributed to the study area becoming a sink habitat, as previously suggested by Petty et al. (2003a). 
In contrast, local breeding population of tawny owls and sparrowhawks did not decline over the study period, despite the substantial increase in the number killed each year by goshawks

(Table 3; Fig. 2). This suggests that goshawk predation on tawny owls and sparrowhawks is compensatory rather than additive. Indeed, the impact of goshawk predation on the local tawny owl population is likely to be mitigated by goshawks selectively killing individuals with low reproductive values (e.g. juveniles and old owls, which have a lower probability of surviving and reproducing than prime-aged adults Millon et al. 2010, 2011), thus reducing the overall impact of predation at the population level (Hoy et al. 2015). Another factor which may be compensating for the increase in goshawk predation on tawny owls is the increase in immigrants entering the local population in recent years (Millon et al. 2014). Hence, goshawk predation may also have led to Kielder becoming a sink habitat for tawny owls. Unfortunately, we do not have equivalent data for sparrowhawks to be able to evaluate whether changes in immigration and/or selective predation of individuals with low reproductive values was also mitigating the impact of increased goshawk predation.

\section{Goshawks have become food-limited}

The substantial decline of two main prey groups (pigeon and game birds) in goshawk diet, the increase in diet diversity and decrease in goshawk reproductive success are all consistent with the goshawk population becoming increasingly food-limited as the population increased. The decline of pigeon and game birds in goshawk diet over the study period (Figs. 2b and 2c), presumably reflected a decline in the availability of two important prey species, namely feral pigeon and red grouse. Although, we cannot directly compare observed changes in the prevalence of feral pigeon and red grouse in diet to changes in their abundance (because regional population trends are not available), there is indirect evidence to suggest that the availability of these two prey species has declined. At a national level there has been a long- 
term decline in red grouse populations in England, and feral pigeon populations are also thought to have declined by 26\% since 1995 (Robinson et al. 2015). The decline in feral pigeons in goshawk diet may also be related to a decline in the number of stray racing pigeons entering the forest, because of a sustained decrease in the number of people participating in pigeon racing since the late 1980's (RPRA 2012). Furthermore, there is also anecdotal evidence of a local decrease in the abundance of red grouse and their main habitat over the study period (M.D., personal observation).

The increase in diet diversity we observed also indirectly supports the notion that there has been a decline in the availability of important prey, because when such food become scarce, predators are forced to switch to alternative species to make up the shortfall. Indeed, diet diversity was found to be negatively related to the abundance of important prey species for both goshawks (Rutz and Bijlsma 2006), sparrowhawks (Millon et al. 2009) and Eagle owls (Bubo bubo; Serrano 2000). Thus, together our results are consistent with goshawks switching to alternative prey species (raptors, corvids and mammals) as the availability of preferred prey species (e.g. feral pigeons and grouse) declined and they become food limited.

The decline in goshawk reproductive success as goshawk numbers increased (Fig. 3) provided additional and independent evidence that goshawks became food-limited given that goshawk reproductive success is known to be positively related to food availability (Rutz and Bijlsma 2006). A decline in reproductive success could also arise if goshawks had smaller home-ranges in high density years. However, this seems unlikely given that the average distance between goshawk nest sites has varied little since the mid-80's (mean distance between nest sites $=3.97$ $\mathrm{km} \pm 0.43$; coefficient of variation $=0.11$ ). A decline in reproductive success with increasing density could also arise if individuals establishing home-ranges in later years were forced to 
settle in "poor-quality sites" because all the "good-quality sites" were already occupied

414 (Rodenhouse et al. 1997). Although the biggest decline in reproductive success was observed in territories established towards the end of the study period, reproductive success also declined in territories established in the early and mid-part of the study period (Appendix 6). One likely reason for the decline in reproductive success, hence food availability being population wide (rather than restricted to certain home-ranges), may be because goshawk hunting ranges overlap (Kenward 2006), such that individuals nesting in the later established "poor-quality sites” may still forage and deplete prey in areas used for hunting by birds nesting in "goodquality site”.

\section{Mechanisms underlying superpredation}

The increase in the proportion of raptors in the diet as goshawk abundance increased (Fig. 1), viewed in combination with the results of other analyses is consistent with predictions for the food-limitation hypothesis of superpredation. That is, as the availability of preferred prey (pigeon and grouse) declined goshawks appear to have switched to alternative, less profitable prey species, such as raptors. Furthermore, predictions of alterative hypotheses were not supported by our data. For example, if superpredation was purely opportunistic then changes in the frequency of mesopredator species in the diet are expected to reflect changes in mesopredator abundance (Polis et al. 1989). However, the contribution of kestrels to goshawk diet was higher in the later part of the study, despite kestrels declining. Furthermore, only two buzzards were known to have been killed by goshawks, despite a substantial increase in the abundance of buzzards in the forest since 1995 (over 80+ home-ranges now occupied). Our results also do not provide support for the predator-removal hypothesis given that the raptor species killed by goshawks were of no or little threat either to adult or juvenile goshawks

437 (Appendix 5). Support for the competitor removal-hypothesis is also lacking because the 
majority (83\%) of raptors killed by goshawks are unlikely to compete with goshawks for food as they are largely dependent on field voles (e.g., kestrels and tawny owls; Appendix 5), yet voles only make up $0.06 \%$ of goshawk diet in terms of biomass. Furthermore, buzzards were seldom preyed upon by goshawks, yet they are known to compete with goshawks for nest sites and kill some of the same species as goshawks (Bijlsma 1994, Krüger 2002a, b). We therefore conclude that food limitation is the most likely driver of superpredation in this system given: 1) the decline in two main prey groups, the increase in diet diversity and the decrease in goshawk reproductive success suggest that the goshawk population has become food-limited; 2) superpredation does not appear to be purely opportunistic, given that variation in goshawk predation on different raptor species did not mirror local mesopredator population trends; and 3) the species of mesopredator killed offer little support for either the predator- or competitorremoval hypotheses of superpredation.

\section{CONCLUSIONS}

Here we have provided evidence to show how superpredation varied over time in a recovering population of an apex predator, the northern goshawk. Our results suggest that increasing rates of superpredation were a response to declining food availability (pigeon and grouse) linked to increasing goshawk numbers. Thus, this study offers insights into the mechanisms driving variation in superpredation. We found evidence suggesting that an increase in goshawk predation may be contributing to a decline in the most frequently predated mesopredator, Eurasian kestrels, a species which is also of conservation concern nationally. Thus, our results indicate that superpredation is likely to be an important factor to consider when developing conservation and management strategies for mesopredator species in the future. However, rather than a shift to a new alternative state, we suggest that the decline in kestrel numbers (and their likely persistence in refuges/areas with lower superpredator abundance) possibly 
represents a reversal of a mesopredator release process (i.e. mesopredator suppression)

464

465

466

467

following the extirpation of goshawks, and decline in other larger raptor species in the UK.

Thus the results presented here may also offer insights into how other raptor communities will change in areas where goshawks are starting to recover. Lastly, in addition to the direct effect that an increase in predation can have on mesopredator population dynamics by increasing mortality rates, it is also important to consider that recovering superpredator populations may also be influencing mesopredator dynamics by negatively affecting mesopredator reproduction success. For example, mesopredators are more likely to abandon breeding attempts when superpredator densities are high (Mueller et al. 2016, Hoy et al. 2016).

\section{ACKNOWLEDGEMENTS}

We are grateful to R. Lourenço and A.K. Mueller for their helpful comments. We thank Forest Research for funding all fieldwork on goshawks during 1973-1996, Forest Enterprise for funding fieldwork after 1998 and T. Dearnley and N. Geddes for allowing and facilitating work in Kielder Forest. This work was also partly funded by a Natural Environment Research Council studentship NE/J500148/1 to SH and a grant NE/F021402/1 to XL and by Natural Research. We thank I. Yoxall and B. Little for the data they collected and their contributions to this study. Lastly, we thank English Nature and the British Trust for Ornithology for kindly issuing licences to monitor goshawk nest sites.

\section{REFERENCES}

Bates, D., Maechler, M., Bolker, B. and Walker, S. 2015. Fitting Linear Mixed-Effects Models Using lme4. - J. Statiscal Softw. in press.

Berger-Tal, O., Mukherjee, S., Kotler, B. P. and Brown, J. S. 2009. Look before you leap: Is risk of injury a foraging cost? - Behav. Ecol. Sociobiol. 63: 1821-1827.

Bijlsma, R. G. 1994. Voedselkeus van Havik Accipiter gentilis, Sperwer A. nisus en Buizerd Buteo buteo in de Flevopolders. - Tak. 2: 22-35.

Burnham, K. P. and Anderson, D. R. 2002. Model Selection and Multimodel Inference: a 
Practical Information-theoretic Approach. - Springer-Verlag.

Caro, T. M. and Stoner, C. J. 2003. The potential for interspecific competition among African carnivores. - Biol. Conserv. 110: 67-75.

Chakarov, N. and Krüger, O. 2010. Mesopredator release by an emergent superpredator: a natural experiment of predation in a three level guild. - PLoS One 5: e15229.

Chapron, G., Kaczensky, P., Linnell, J. D. C., von Arx, M., Huber, D., Andrén, H., LópezBao, J. V., Adamec, M., Álvares, F., Anders, O., Balčiauskas, L., Balys, V., Bedő, P., Bego, F., Blanco, J. C., Breitenmoser, U., Brøseth, H., Bufka, L., Bunikyte, R., Ciucci, P., Dutsov, A., Engleder, T., Fuxjäger, C., Groff, C., Holmala, K., Hoxha, B., Iliopoulos, Y., Ionescu, O., Jeremić, J., Jerina, K., Kluth, G., Knauer, F., Kojola, I., Kos, I., Krofel, M., Kubala, J., Kunovac, S., Kusak, J., Kutal, M., Liberg, O., Majić, A., Männil, P., Manz, R., Marboutin, E., Marucco, F., Melovski, D., Mersini, K., Mertzanis, Y., Mysłajek, R. W., Nowak, S., Odden, J., Ozolins, J., Palomero, G., Paunović, M., Persson, J., Potočnik, H., Quenette, P.-Y., Rauer, G., Reinhardt, I., Rigg, R., Ryser, A., Salvatori, V., Skrbinšek, T., Stojanov, A., Swenson, J. E., Szemethy, L., Trajçe, A., Tsingarska-Sedefcheva, E., Váňa, M., Veeroja, R., Wabakken, P., Wölfl, M., Wölfl, S., Zimmermann, F., Zlatanova, D. and Boitani, L. 2014. Recovery of large carnivores in Europe’s modern human-dominated landscapes. - Science (80-. ). 346: 1517-1519.

Cornulier, T., Yoccoz, N. G., Bretagnolle, V., Brommer, J. E., Butet, A., Ecke, F., Elston, D. a, Framstad, E., Henttonen, H., Hörnfeldt, B., Huitu, O., Imholt, C., Ims, R. a, Jacob, J., Jędrzejewska, B., Millon, A., Petty, S. J., Pietiäinen, H., Tkadlec, E., Zub, K. and Lambin, X. 2013. Europe-wide dampening of population cycles in keystone herbivores. - Science (80-. ). 340: 63-6.

Crooks, K. R. and Soulé, M. E. 1999. Mesopredator release and avifaunal extinctions in a fragmented system. - Nature 400: 563-566.

Deinet, S., Ieronymidou, C., McRae, L., Burfield, I. J., Foppen, R. P., Collen, B. and Böhm, M. 2013. Wildlife comeback in Europe: The recovery of selected mammal and bird species.

Hoy, S. R., Petty, S. J., Millon, A., Whitfield, D. P., Marquiss, M., Davison, M. and Lambin, X. 2015. Age and sex-selective predation as moderators of the overall impact of predation. - J. Anim. Ecol. 84: 692-701.

Hoy, S. R., Millon, A., Petty, S. J., Whitfield, D. P. and Lambin, X. 2016. Food availability and predation risk, rather than intrinsic attributes, are the main factors shaping the reproductive decisions of a long-lived predator. - J. Anim. Ecol. 85: 892-902.

Kenward, R. E. 2006. The Goshawk. - T \& A D Poyser.

Krüger, O. 2002a. Interactions between common buzzard Buteo buteo and goshawk Accipiter gentilis: trade-offs revealed by a field experiment. - Oikos 96: 441-452.

Krüger, O. 2002b. Analysis of nest occupancy and nest reproduction in two sympatric raptors: common buzzard Buteo buteo and goshawk Accipiter gentilis. - Ecography (Cop.). 25: 523-532.

Little, B., Davison, M. and Jardine, D. 1995. Merlins Falco columbarius in Kielder Forest: influences of habitat on breeding performance. - For. Ecol. Manage. 79: 147-152.

Lourenço, R., Santos, S. M., Rabaça, J. E. and Penteriani, V. 2011a. Superpredation patterns in four large European raptors. - Popul. Ecol. 53: 175-185.

Lourenço, R., Penteriani, V., Delgado, M. D. M., Marchi-Bartolozzi, M. and Rabaça, J. E. 
2011b. Kill before being killed: an experimental approach supports the predator-removal hypothesis as a determinant of intraguild predation in top predators. - Behav. Ecol. Sociobiol.: 1709-1714.

Maehr, D. S., Noss, R. F. and Larkin, J. L. 2001. Large Mammal Restoration: Ecological and Sociological Challenges in the 21st Century. - Island Press.

Marquiss, M. and Newton, I. 1982. The goshawk in Britain. - Br. Birds 75: 243-260.

Millon, A., Arroyo, B. E. and Bretagnolle, V. 2008. Variable but predictable prey availability affects predator breeding success: natural versus experimental evidence. - J. Zool. 275: 349-358.

Millon, A., Nielsen, J. T., Bretagnolle, V. and Møller, A. P. 2009. Predator-prey relationships in a changing environment: The case of the sparrowhawk and its avian prey community in a rural area. - J. Anim. Ecol. 78: 1086-1095.

Millon, A., Petty, S. J. and Lambin, X. 2010. Pulsed resources affect the timing of first breeding and lifetime reproductive success of tawny owls. - J. Anim. Ecol. 79: 426-435.

Millon, A., Petty, S. J., Little, B. and Lambin, X. 2011. Natal conditions alter age-specific reproduction but not survival or senescence in a long-lived bird of prey. - J. Anim. Ecol. 80: 968-975.

Millon, A., Petty, S. J., Little, B., Gimenez, O., Cornulier, T. and Lambin, X. 2014. Dampening prey cycle overrides the impact of climate change on predator population dynamics: A long-term demographic study on tawny owls. - Glob. Chang. Biol. 20: 1770-1781.

Mueller, A.-K., Chakarov, N., Heseker, H. and Krüger, O. 2016. Intraguild predation leads to cascading effects on habitat choice, behaviour and reproductive performance (J Quinn, Ed.). - J. Anim. Ecol. 85: 774-784.

Newton, I. 1979. Population ecology of raptors. - T. and A.D. Poyser.

Newton, I. 1998. Population limitation in birds. - Academic Press.

Newton, I., Meek, E. and Little, B. 1986. Population and breeding of Northumbrian Merlins. - Br. Birds 79: 155-170.

Paine, R. T. 1980. Food webs: linkage, interaction strength, and community infrastructure. J. Anim. Ecol. 49: 667-685.

Palomares, F. and Caro, T. M. 1999. Interspecific killing among mammalian carnivores. Am. Nat. 153: 492-508.

Petty, S. J. 1979. Breeding biology of the sparrowhawk in Kielder Forest 1975-78. - In: Galloway, B. and Hodgson, M. S. (eds), Birds in Northumbria: 1978 Northumberland bird report. Tyneside bird club, pp. 92-109.

Petty, S. J. 1992. Ecology of the Tawny owl Strix aluco in the spruce forests of Northumberland and Argyll.

Petty, S. J. 1996. History of Northern Goshawk Accipiter gentilis in Britain. - In: Holmes, J. S. and Simons, J. R. (eds), The Introduction and Naturalisation of Birds. The Stationery Office, pp. 95-102.

Petty, S. J. and Anderson, D. I. K. 1995. Goshawks Accipiter gentilis. - In: Day, J. C. et al. (eds), The Atlas of Breeding Birds in Northumbria. Newcastle upon Tyne: Northumberland and Tyneside Bird Club, pp. 44-45.

Petty, S. J., Shaw, G. and Anderson, D. I. K. 1994. Value of nest boxes for population studies 

and conservation of owls in coniferous forests in Britain. - J. Raptor Res. 28: 134-142.

Petty, S. J., Patterson, I. J., Anderson, D. I. K., Little, B. and Davison, M. 1995. Numbers, breeding performance, and diet of the sparrowhawk Accipiter nisus and merlin Falco columbarius in relation to cone crops and seed-eating finches. - For. Ecol. Manage. 79: 133-146.

Petty, S. J., Anderson, D. I. K., Davison, M., Little, B., Sherratt, T. N., Thomas, C. J. and Lambin, X. 2003a. The decline of common kestrels Falco tinnunculus in a forested area of northern England: the role of predation by Northern Goshawks Accipiter gentilis. Ibis (Lond. 1859). 145: 472-483.

Petty, S. J., Lurz, P. W. W. and Rushton, S. P. 2003b. Predation of red squirrels by northern goshawks in a conifer forest in northern England : can this limit squirrel numbers and create a conservation dilemma ? - Biol. Conserv. 111: 105-114.

Polis, G. A., Myers, C. A. and Holt, R. D. 1989. The ecology and evolution of intraguild predation: Potential Competitors That Eat Each Other. - Annu. Rev. Ecol. Syst. 20: 297330.

R Core Development Team 2015. R Development Core Team. - R A Lang. Environ. Stat. Comput. . R Found. Stat. Comput. , Vienna, Austria. URL http//www.R-project.org/. in press.

Ripple, W. J. and Beschta, R. L. 2004. Wolves and the ecology of fear : can predation risk structure ecosystems ? - Bioscience 54: 755-766.

Ritchie, E. G. and Johnson, C. N. 2009. Predator interactions, mesopredator release and biodiversity conservation. - Ecol. Lett. 12: 982-998.

Robinson, R. A., Marchant, J. H., Leech, D. I., Massimino, D., Sullivan, M. J. P., Eglington, S. M., Barimore, C., Dadam, D., Downie, I. S., Hammond, M. J., Harris, S. J., Noble, D. G., Walker, R. H. and Baillie, S. R. 2015. BirdTrends 2015: trends in numbers, breeding success and survival for UK breeding birds. Research Report 678.

Rodenhouse, N. L., Sherry, T. W. and Holmes, R. T. 1997. Site-dependent regulation of population size: a new synthesis. - Ecology 78: 2025-2042.

RPRA 2012. Royal Pigeon Racing Association .: http://www.rpra.org.

Rutz, C. and Bijlsma, R. G. 2006. Food-limitation in a generalist predator. - Proc. R. Soc. Biol. Sci. 273: 2069-76.

Rutz, C., Bijlsma, R. G., Marquiss, M. and Kenward, R. E. 2006. Population limitation in the northern goshawk in Europe: a review with case studies. - Stud. Avian Biol.: 158-197.

Sergio, F. and Hiraldo, F. 2008. Intraguild predation in raptor assemblages: a review. - Ibis (Lond. 1859). 150: 132-145.

Serrano, D. 2000. Relationship between raptors and rabbits in the diet of eagle owls in southwestern Europe: competition removal or food stress? - J. Raptor Res. 34: 305-310.

Soulé, M. ., Bolger, D. ., Alberts, A. ., Wright, J., Sorice, M. and Hill, S. 1988. Reconstructed of rapid extinctions of dynamics birds in urban habitat islands. - Conserv. Biol. 2: 7592.

Toyne, E. P. 1998. Breeding season diet of the Goshawk Accipiter gentilis in Wales. - Ibis (Lond. 1859). 140: 569-579.

Wood, S. 2015. Package: mgcv 1.8-9 Mixed GAM Computation Vehicle with GCV/AIC/REML Smoothness Estimation. - R 3.2.3 
623 Ziesemer, F. 1983. Untersuchungen zum Einfluss des Habichts (Accipiter gentilis) auf 624 Populationen seiner Beutetiere.

625 
Table 1. Model selection and parameters for the analysis of variation in the proportion of goshawk diet comprised of all raptor species and also kestrels, tawny owls and sparrowhawks separately. We examined whether diet varied in relation to goshawk abundance (number of home-ranges occupied) and the altitude of the goshawk home-range (e.g., below 225m, between 226-354m and above 355m). The most parsimonious model will have a $\Delta \mathrm{AICc}=0$ and is highlighted in bold. The number of parameters estimated in each model is designated in the $n p$ column. AICc weights $(W)$ are an estimate of the relative likelihood of a model.

\begin{tabular}{|c|c|c|c|c|c|c|c|c|c|c|c|c|c|c|c|c|c|c|}
\hline & \multirow{2}{*}{ Model } & \multirow[b]{2}{*}{$n p$} & \multicolumn{4}{|c|}{ All raptors } & \multicolumn{4}{|c|}{ Kestrel } & \multicolumn{4}{|c|}{ Tawny owl } & \multicolumn{4}{|c|}{ Sparrowhawk } \\
\hline & & & Estimate & $\mathrm{SE}$ & $\triangle \mathrm{AICc}$ & $W$ & Estimate & $\mathrm{SE}$ & $\triangle \mathrm{AICc}$ & $W$ & Estimate & $\mathrm{SE}$ & $\triangle \mathrm{AICc}$ & $W$ & Estimate & SE & $\triangle \mathrm{AICc}$ & $W$ \\
\hline 1. & Null & 2 & & & 26.74 & $<0.01$ & & & 11.87 & $<0.01$ & & & 13.51 & $<0.01$ & & & 9.36 & 0.01 \\
\hline 2. & Goshawk abundance (GA) & 4 & 0.06 & 0.02 & 14.46 & $<0.01$ & 0.02 & 0.02 & 12.53 & $<0.01$ & 0.11 & 0.03 & $\mathbf{0}$ & 0.84 & 0.12 & 0.04 & $\mathbf{0}$ & 0.61 \\
\hline \multirow[t]{2}{*}{3.} & Altitude (226-354m) & 5 & -0.01 & 0.19 & 13.2 & $<0.01$ & -0.18 & 0.26 & 2.7 & 0.18 & 0.15 & 0.35 & 17.09 & $<0.01$ & -0.2 & 0.49 & 9.89 & $<0.01$ \\
\hline & Altitude (above 355m) & & 0.95 & 0.28 & & & 0.96 & 0.38 & & & 0.36 & 0.52 & & & 0.92 & 0.76 & & \\
\hline \multirow[t]{3}{*}{4.} & Altitude (226-354m) & 6 & 0.03 & 0.18 & 4.89 & 0.08 & -0.15 & 0.25 & 3.94 & 0.1 & 0.22 & 0.34 & 3.66 & 0.13 & -0.12 & 0.47 & 2.66 & 0.16 \\
\hline & Altitude (above 355m) & & 0.84 & 0.27 & & & 0.95 & 0.38 & & & 0.14 & 0.5 & & & 0.58 & 0.72 & & \\
\hline & + Goshawk abundance & & 0.05 & 0.02 & & & 0.02 & 0.02 & & & 0.11 & 0.03 & & & 0.11 & 0.04 & & \\
\hline \multirow[t]{5}{*}{5.} & Altitude (226-354m) & 8 & -0.87 & 0.68 & $\mathbf{0}$ & 0.92 & -0.98 & 0.93 & $\mathbf{0}$ & 0.71 & -0.72 & 1.62 & 6.94 & 0.03 & -4.18 & 1.94 & 2.07 & 0.22 \\
\hline & Altitude (above 355m) & & 2.57 & 1.01 & & & 3.18 & 1.26 & & & -2.98 & 3.73 & & & -1.22 & 3.97 & & \\
\hline & Goshawk abundance & & 0.03 & 0.03 & & & 0.01 & 0.04 & & & 0.08 & 0.06 & & & 0.01 & 0.06 & & \\
\hline & Altitude (226-354m) x GA & & 0.04 & 0.03 & & & 0.04 & 0.04 & & & 0.04 & 0.06 & & & 0.16 & 0.08 & & \\
\hline & Altitude (above 355m) x GA & & -0.07 & 0.04 & & & -0.09 & 0.05 & & & 0.11 & 0.13 & & & 0.07 & 0.15 & & \\
\hline
\end{tabular}


Table 2. The 10 most important prey species in northern goshawk breeding season diet, ranked in order of decreasing importance in terms of both their frequency in the diet and biomass contribution to diet when the number of occupied goshawk home-ranges was estimated to be less than 14, between 15-24 and 25 or more.

\begin{tabular}{|c|c|c|c|c|c|c|c|c|c|c|}
\hline \multirow[b]{2}{*}{$\begin{array}{l}\text { Species } \\
\text { rank }\end{array}$} & \multicolumn{6}{|c|}{ Frequency } & \multirow[b]{2}{*}{$\begin{array}{l}\text { Species } \\
\text { rank }\end{array}$} & \multicolumn{3}{|c|}{ Biomass } \\
\hline & $\begin{array}{c}<14 \text { occupied } \\
\text { goshawk home- } \\
\text { ranges }\end{array}$ & $n$ & $\begin{array}{c}\text { 15-24 occupied } \\
\text { goshawk home- } \\
\text { ranges }\end{array}$ & $n$ & $\begin{array}{c}>25 \text { occupied } \\
\text { goshawk home- } \\
\text { ranges }\end{array}$ & $n$ & & $\begin{array}{c}<14 \text { occupied } \\
\text { goshawk home- } \\
\text { ranges }\end{array}$ & $\begin{array}{c}\text { 15-24 occupied } \\
\text { goshawk home- } \\
\text { ranges }\end{array}$ & $\begin{array}{c}>25 \text { occupied } \\
\text { goshawk home- } \\
\text { ranges }\end{array}$ \\
\hline 1. & Feral pigeon & 531 & Wood pigeon & 848 & Wood pigeon & 625 & 1. & Wood pigeon & Wood pigeon & Wood pigeon \\
\hline 2. & Wood pigeon & 488 & Feral pigeon & 752 & Feral pigeon & 479 & 2. & Red grouse & Crow/rook & Crow/rook \\
\hline 3. & Red grouse & 277 & Crow/rook & 597 & Crow/rook & 383 & 3. & Feral pigeon & Feral pigeon & Rabbit \\
\hline 4. & Crow/rook & 149 & Red grouse & 221 & Red grouse & 133 & 4. & Crow/rook & Rabbit & Feral pigeon \\
\hline 5. & Jay & 35 & Kestrel & 128 & Rabbit & 108 & 5. & Rabbit & Red grouse & Red grouse \\
\hline 6. & Song thrush & 30 & Rabbit & 126 & Red squirrel & 89 & 6. & Pheasant & Pheasant & Pheasant \\
\hline 7. & Mistle thrush & 27 & Mistle thrush & 85 & Mistle thrush & 88 & 7. & European hare & Kestrel & Tawny owl \\
\hline 8. & Field vole & 25 & Red squirrel & 84 & Jay & 78 & 8. & Jay & Red squirrel & Red squirrel \\
\hline 9. & Kestrel & 24 & Song thrush & 78 & Kestrel & 76 & 9. & Mallard & Tawny owl & Kestrel \\
\hline 10. & Red squirrel & 22 & Jay & 61 & Tawny owl & 69 & 10. & Kestrel & Mistle thrush & Jay \\
\hline
\end{tabular}


Table 3. Estimated number of kestrels, tawny owls and sparrowhawks killed during the breeding season (March-August) each year by the Kielder Forest goshawk population when the number of occupied goshawk home-ranges was estimated to be less than 14, between 15-24 and 25 or more.

\begin{tabular}{|c|c|c|c|c|c|c|}
\hline Species & $\begin{array}{l}\text { Occupied goshawk } \\
\text { home-ranges }\end{array}$ & $\begin{array}{c}\text { Estimated \% biomass } \\
\text { of goshawk diet }\end{array}$ & $\begin{array}{l}\text { Average number } \\
\text { killed per pair }\end{array}$ & $\begin{array}{l}\text { Mean number killed } \\
\text { each year the by entire } \\
\text { goshawk population }\end{array}$ & $\begin{array}{l}\text { 95\% CI } \\
\text { lower bound }\end{array}$ & $\begin{array}{l}95 \% \text { CI } \\
\text { upper bound }\end{array}$ \\
\hline \multirow{3}{*}{ Kestrel } & $<14$ & 0.47 & 2.20 & 14 & 11 & 18 \\
\hline & $15-24$ & 2.29 & 10.23 & 223 & 197 & 248 \\
\hline & $>25$ & 1.63 & 6.44 & 176 & 154 & 198 \\
\hline \multirow{3}{*}{ Tawny owl } & $<14$ & 0.34 & 0.70 & 5 & 3 & 6 \\
\hline & $15-24$ & 1.69 & 3.33 & 72 & 62 & 83 \\
\hline & $>25$ & 3.32 & 5.79 & 159 & 141 & 176 \\
\hline \multirow{3}{*}{ Sparrowhawk } & $<14$ & 0.04 & 0.21 & 1 & 1 & 2 \\
\hline & $15-24$ & 0.37 & 1.66 & 36 & 28 & 45 \\
\hline & $>25$ & 0.48 & 1.92 & 53 & 44 & 61 \\
\hline
\end{tabular}


Table 4. Model selection and parameters for the analysis of variation in the proportion of goshawk diet comprised of different prey groups (pigeons, corvids, game birds, mammals and other). We examined whether diet varied in relation to goshawk abundance (number of home-ranges occupied) and the altitude of the goshawk home-range (e.g., below 225m, between 226-354m and above 355m). The most parsimonious model will have a $\Delta \mathrm{AICc}=0$ and is highlighted in bold. The number of parameters estimated in each model is designated in the $n p$ column. AICc weights $(W)$ are an estimate of the relative likelihood of a model.

\begin{tabular}{|c|c|c|c|c|c|c|c|c|c|c|c|c|c|c|c|c|c|c|c|c|c|}
\hline \multirow{2}{*}{ Model } & \multirow[b]{2}{*}{$n p$} & \multicolumn{4}{|c|}{ Pigeons } & \multicolumn{4}{|c|}{ Corvids } & \multicolumn{4}{|c|}{ Game birds } & \multicolumn{4}{|c|}{ Mammals } & \multicolumn{4}{|c|}{ Other } \\
\hline & & Estimate & $\mathrm{SE}$ & $\triangle \mathrm{AICc}$ & $W$ & Estimate & $\mathrm{SE}$ & $\triangle \mathrm{AICc}$ & $W$ & Estimate & $\mathrm{SE}$ & $\triangle \mathrm{AICc}$ & $W$ & Estimate & $\mathrm{SE}$ & $\triangle \mathrm{AICc}$ & $W$ & Estimate & $\mathrm{SE}$ & $\triangle \mathrm{AICc}$ & $W$ \\
\hline Null & 2 & & & 16.82 & $<0.01$ & & & 7.94 & 0.02 & & & 23.01 & $<0.01$ & & & 2.60 & 0.19 & & & 6.77 & 0.03 \\
\hline Goshawk abundance (GA) & 4 & -0.02 & 0.01 & 10.49 & $<0.01$ & 0.04 & 0.01 & $\mathbf{0}$ & 0.8 & -0.03 & 0.01 & 9.66 & 0.01 & 0.03 & 0.01 & $\mathbf{0}$ & 0.68 & 0.03 & 0.01 & $\mathbf{0}$ & 0.77 \\
\hline Altitude (226-354m) & 5 & 0.04 & 0.10 & 4.04 & 0.08 & -0.11 & 0.12 & 10.96 & $<0.01$ & 0.32 & 0.22 & 22.75 & $<0.01$ & -0.05 & 0.17 & 6.55 & 0.03 & -0.05 & 0.13 & 9.21 & 0.01 \\
\hline Altitude (above 355m) & & -0.42 & 0.15 & & & -0.02 & 0.19 & & & 0.55 & 0.26 & & & 0.001 & 0.26 & & & 0.16 & 0.20 & & \\
\hline Altitude (226-354m) & 6 & 0.03 & 0.10 & $\mathbf{0}$ & 0.62 & -0.09 & 0.12 & 3.55 & 0.14 & 0.29 & 0.21 & $\mathbf{0}$ & 0.64 & -0.03 & 0.17 & 4.04 & 0.09 & -0.04 & 0.13 & 3.20 & 0.16 \\
\hline Altitude (above 355m) & & -0.40 & 0.15 & & & -0.04 & 0.19 & & & 0.85 & 0.26 & & & -0.06 & 0.26 & & & 0.12 & 0.20 & & \\
\hline + Goshawk abundance & & -0.02 & 0.01 & & & 0.04 & 0.01 & & & -0.04 & 0.01 & & & 0.03 & 0.01 & & & 0.03 & 0.01 & & \\
\hline Altitude (226-354m) & 8 & -0.29 & 0.34 & 1.54 & 0.29 & -0.12 & 0.42 & 5.96 & 0.04 & 0.30 & 0.60 & 1.15 & 0.36 & 0.01 & 0.64 & 7.76 & 0.01 & 0.32 & 0.49 & 6.10 & 0.04 \\
\hline Altitude (above 355m) & & -1.29 & 0.60 & & & 0.77 & 0.71 & & & -0.78 & 1.15 & & & -0.83 & 1.39 & & & 1.03 & 0.89 & & \\
\hline Goshawk abundance & & -0.03 & 0.01 & & & 0.04 & 0.02 & & & -0.04 & 0.02 & & & 0.03 & 0.03 & & & 0.05 & 0.02 & & \\
\hline Altitude (226-354m) x GA & & 0.01 & 0.01 & & & 0.002 & 0.02 & & & -0.001 & 0.03 & & & -0.002 & 0.03 & & & -0.01 & 0.02 & & \\
\hline Altitude (above 355m) x GA & & 0.04 & 0.02 & & & -0.03 & 0.03 & & & 0.06 & 0.04 & & & 0.03 & 0.05 & & & -0.04 & 0.03 & & \\
\hline
\end{tabular}


Figure Legends

Figure 1. Changes in the proportion of northern goshawk breeding season diet comprised of: a) raptors; b) pigeons; c) corvids; d) mammals; e) game birds and f) other species as the number of occupied goshawk home-ranges increased in Kielder Forest, UK. Error bars are the 95\% confidence intervals.

Figure 2. Changes in the proportion of northern goshawk breeding season diet comprised of: a) kestrels; b) tawny owls; c) sparrowhawks as the number of occupied goshawk home-ranges increased in Kielder Forest, UK. Error bars are the 95\% confidence intervals.

Figure 3. Inter-annual variation in goshawk reproductive success measured as: a) the number of chicks fledged per successful breeding attempt (line represents predicted values generated from a GAM) and b) the proportion of breeding attempts which were successful (line represents predicted values generated from a GLM) as the number of occupied goshawk home-ranges increased in Kielder Forest, UK. 
a)
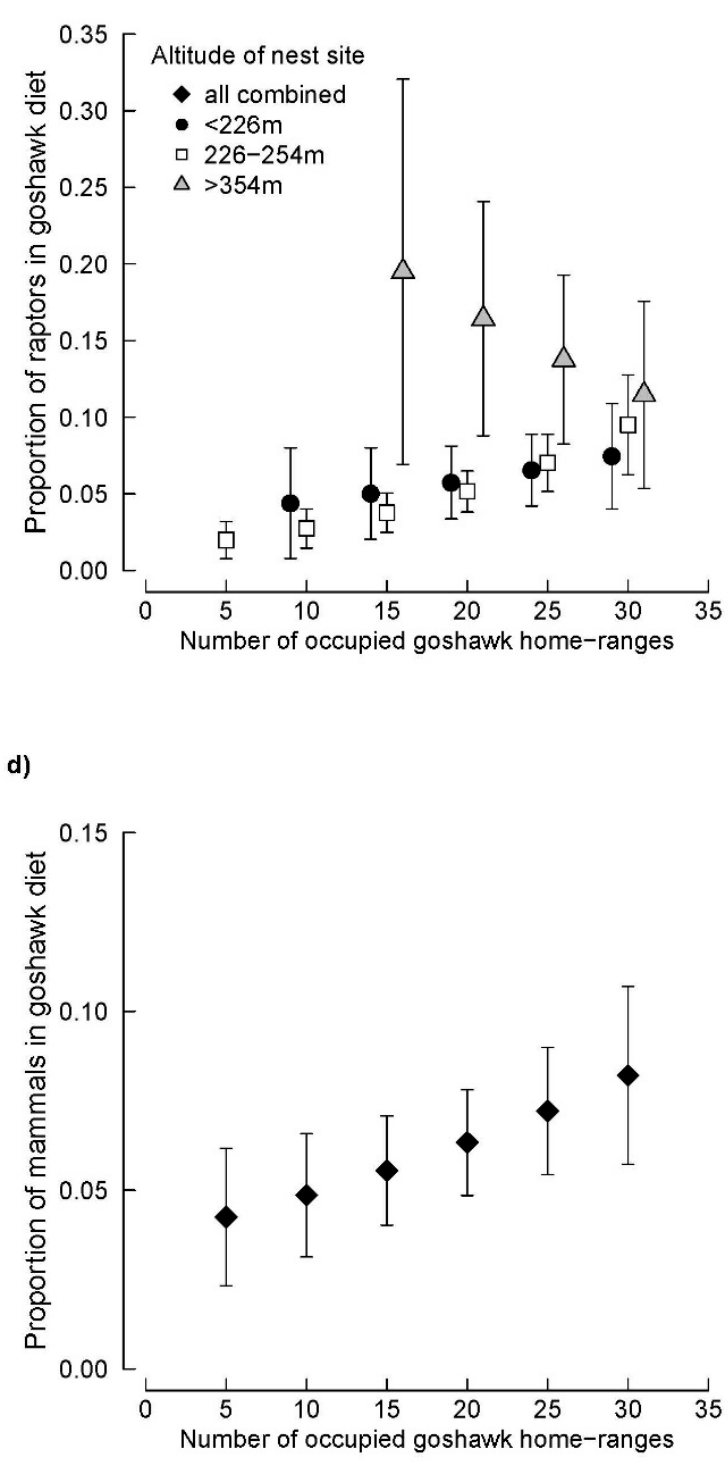

b)

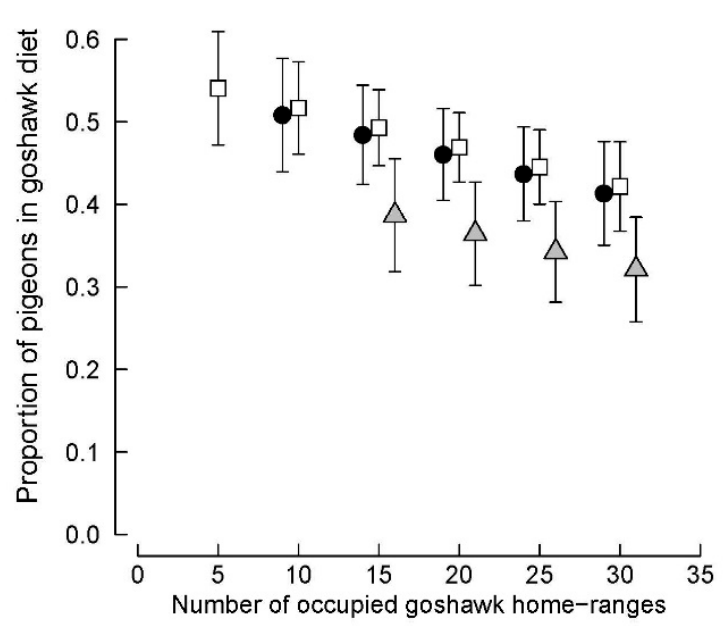

e)

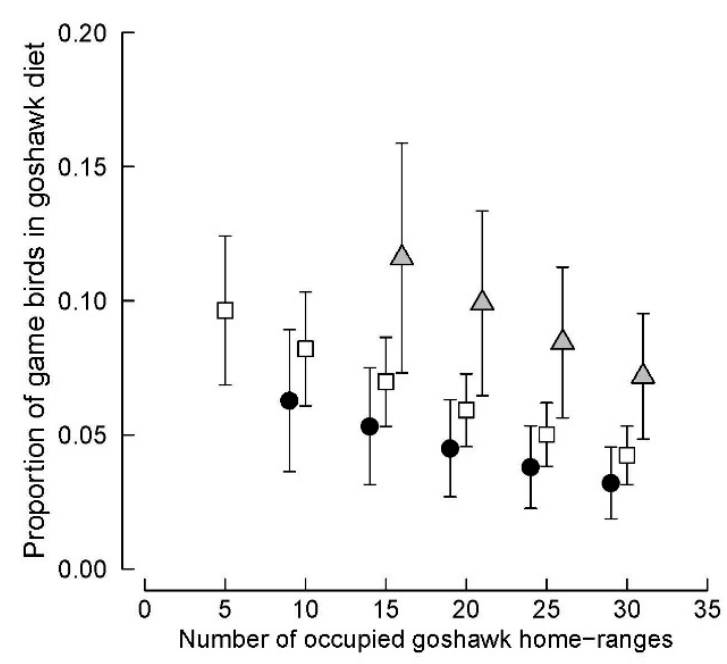

c)

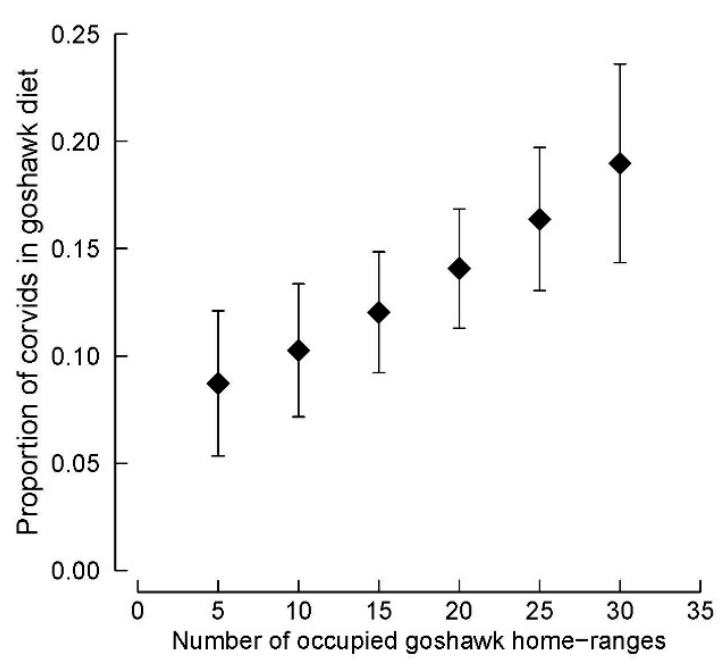

f)

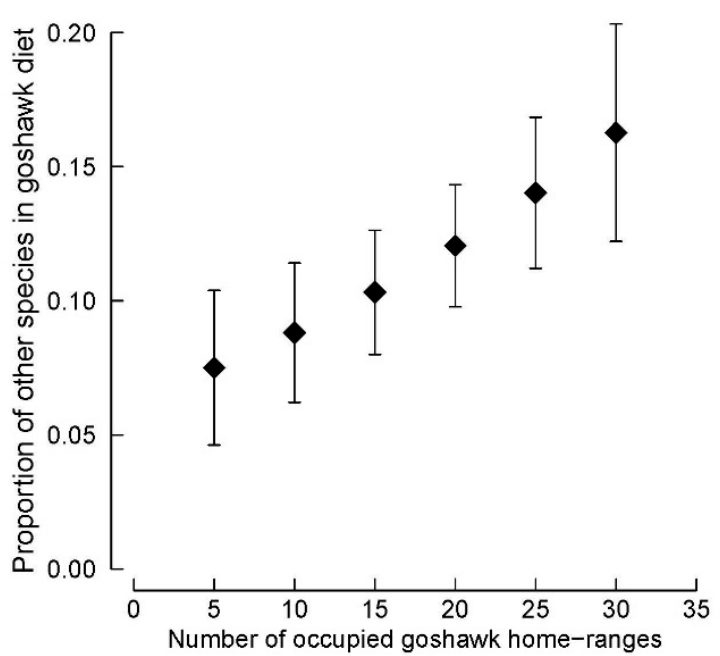


a)

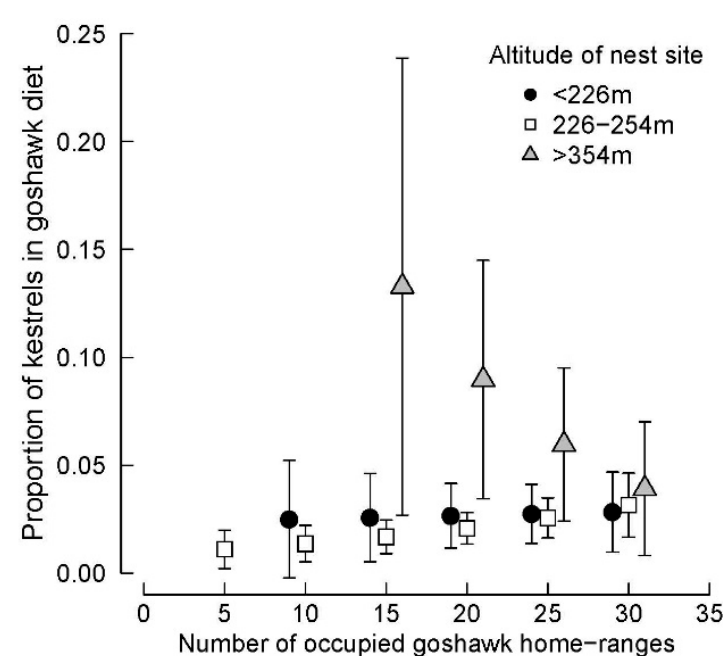

b)

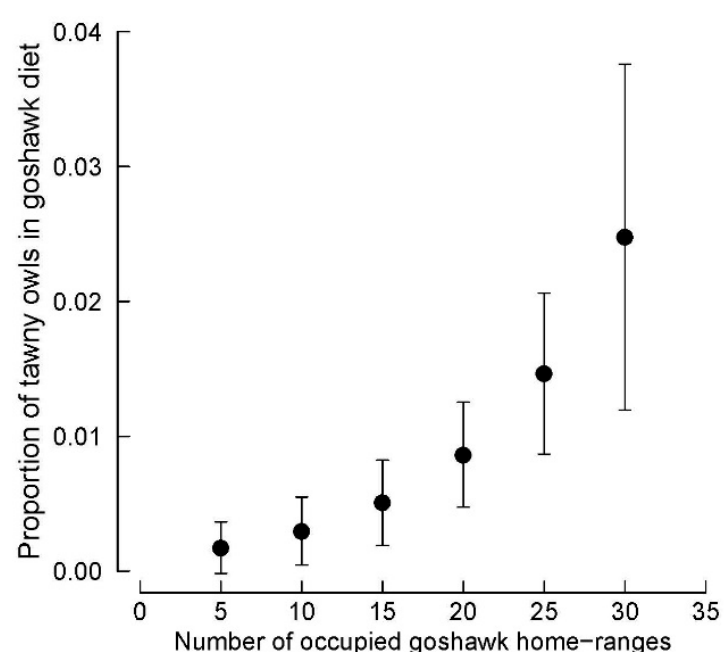

c)

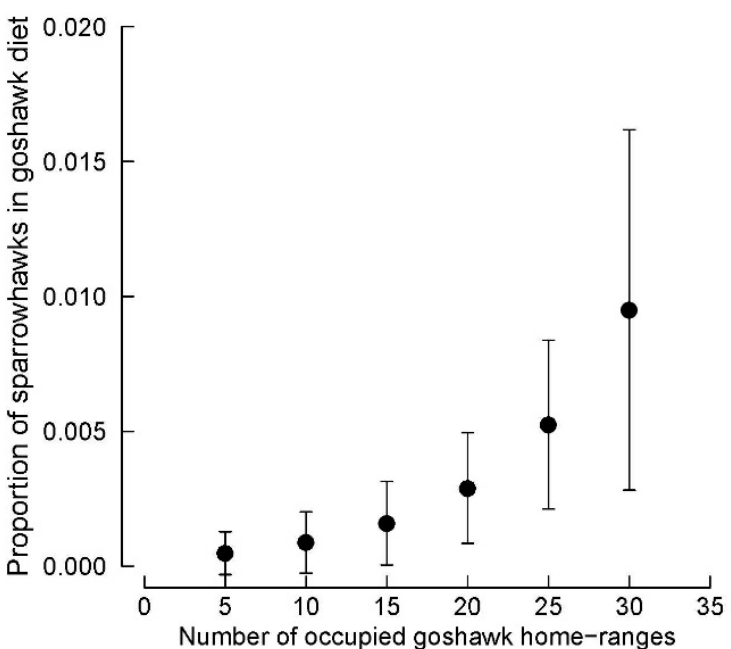




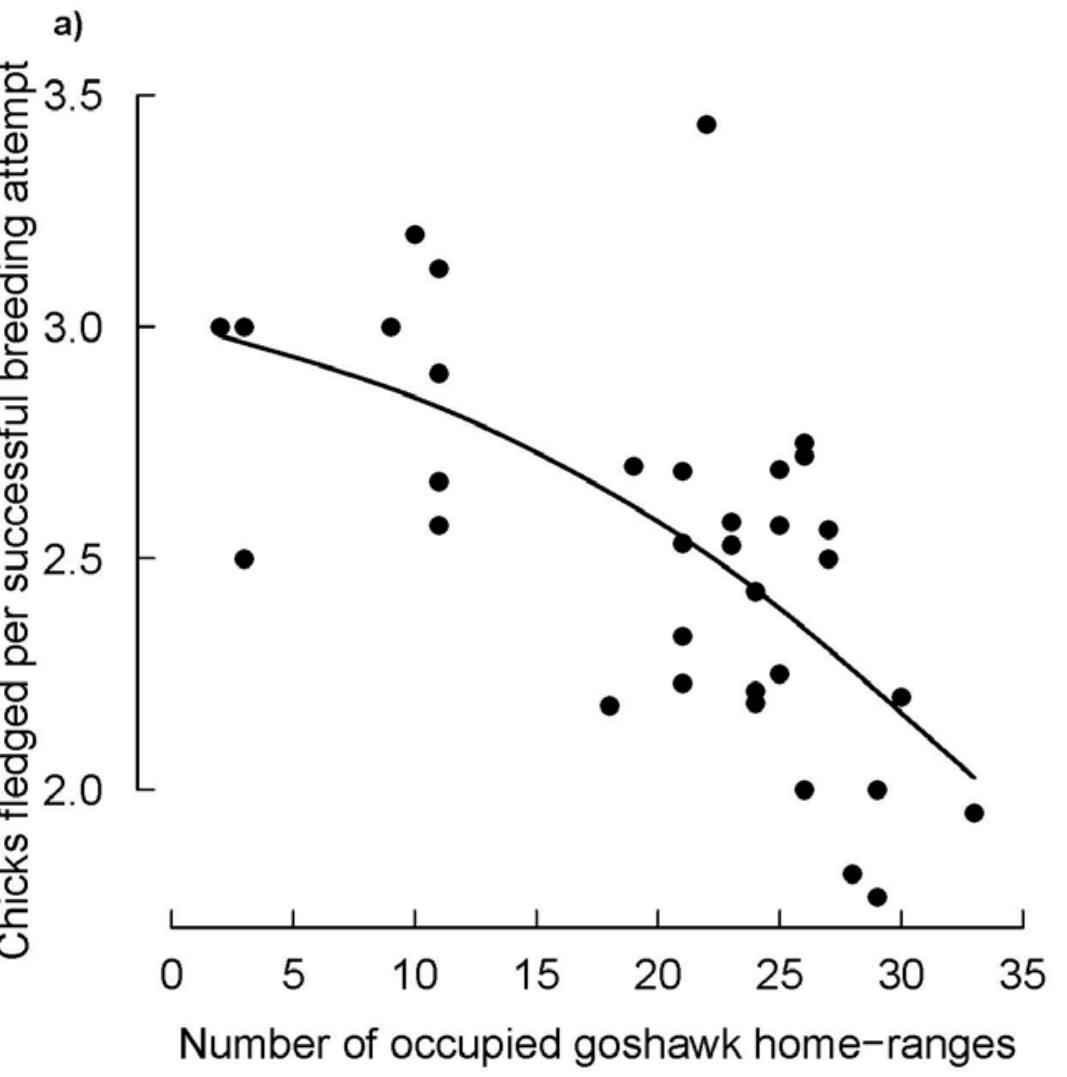

b)

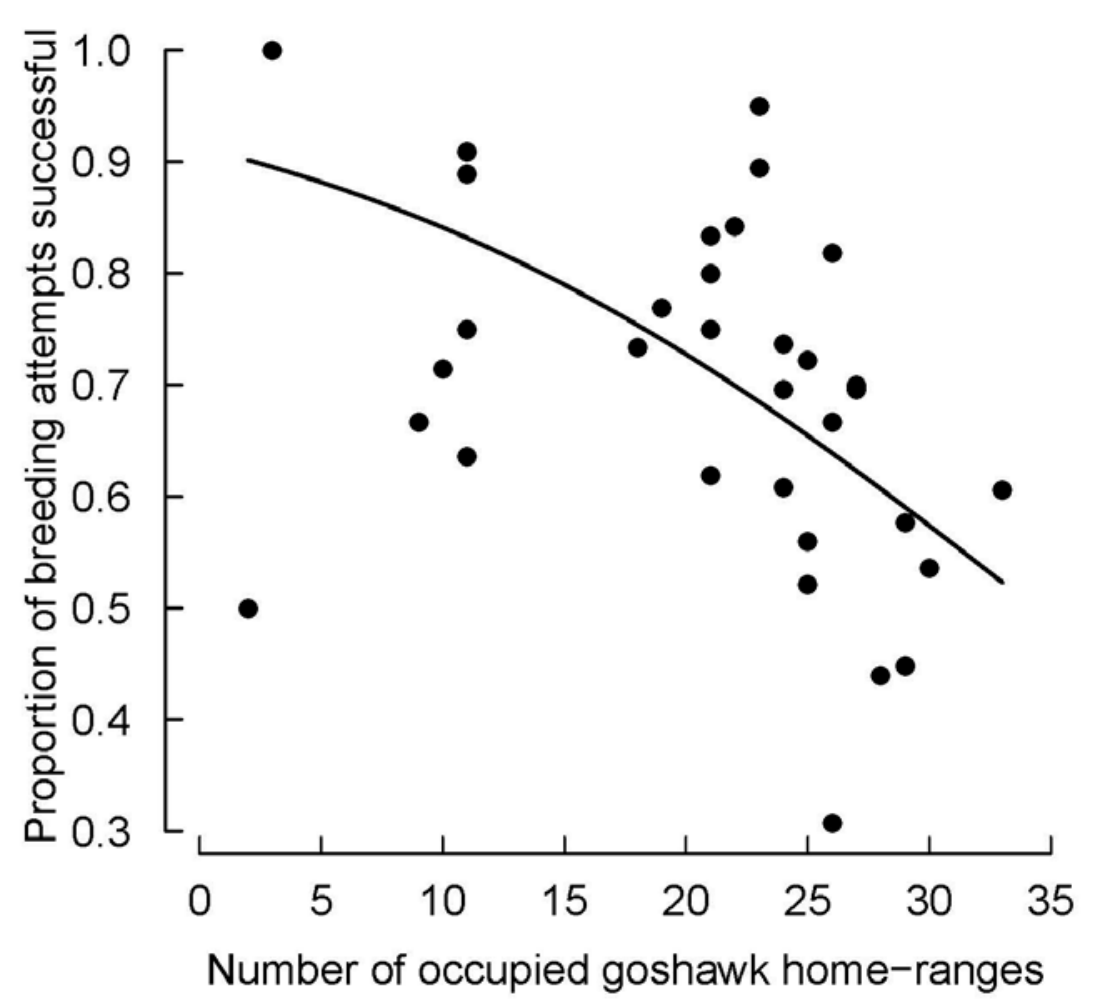


Appendix 1: The number of occupied northern goshawk home-ranges in Kielder Forest, UK

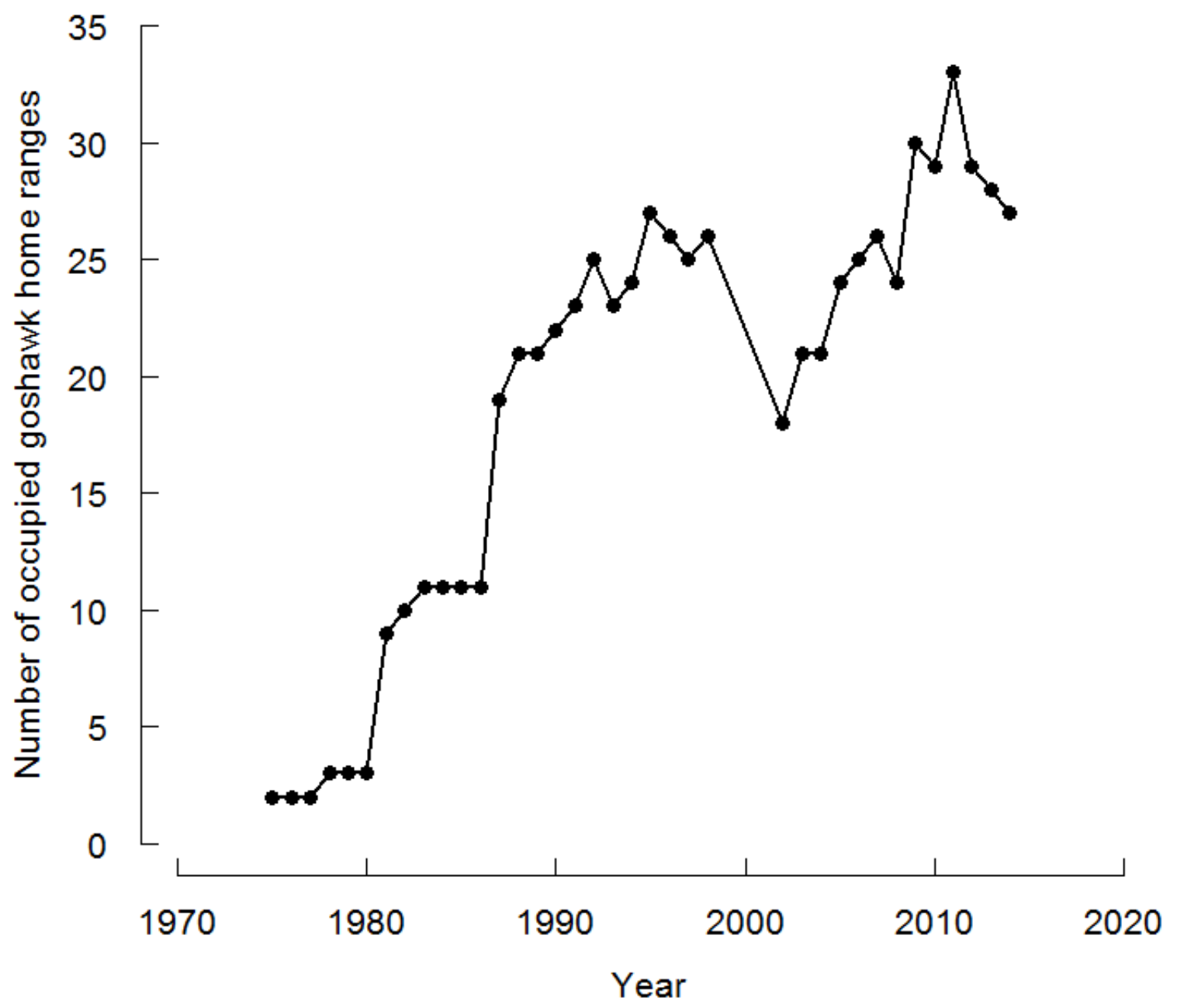


Appendix 2: The average number of kestrels, tawny owls and sparrowhawks killed by the goshawk population each year

To estimate the average number of each species killed by the goshawk population each year, we first calculated the average number of each species killed per pair of goshawks, each year when 1-14, 15-24 and 25+ goshawk home-ranges were occupied, using the following equation taken from Petty et al. (2003).

$\mathrm{IK}=(\mathrm{CF}+\mathrm{CM}+\mathrm{CY}) *(\mathrm{PT}) / \mathrm{M}$

IK is the estimated number of individuals killed by a pair of goshawks between March and August (184 days). CF = estimated total food consumption of a female goshawk during the breeding season (189g of food per day * 184 days). CM $=$ total food consumption of a male goshawk during the breeding season (133g of food per day * 184 days). The daily food consumption values used for male and female goshawk are the same as those used by Petty et al. (2003), originally calculated by Kenward et al. (1981). CY = total food consumption of young goshawks (i.e. offspring) during the breeding season (161g of food per day (CF+CM/2) * 108 days * mean fledged brood size of breeding pairs). The mean fledged brood size of goshawks was 2.19 in years when fewer than 15 home-ranges were occupied, 1.93 when 1524 home-ranges were occupied and 1.31 when 25 or more home-ranges were occupied. The CY estimate assumes that young goshawks: 1) hatch around mid-May; 2) do not leave their natal territory until August; and 3) that juveniles have the same overall food intake as adults. Although young nestlings require less food than adults, older nestlings require more, such that when averaged over the entire period nestling food intake can be assumed to be equivalent to that of adults. $\mathrm{M}=$ average mass of the prey species. We used an average mass of $208 \mathrm{~g}$ for kestrel (Ratcliffe 1993); 470g for tawny owl and 205g for sparrowhawk (Robinson 2005). PT = proportion biomass of the prey species in the diet. We used the dietary data to estimate of the proportion biomass of each of the three mesopredator species in goshawk diet for each of the three goshawk abundance categories (i.e. using pooled annual diet data collected when the number of occupied goshawk home-ranges was 1-14, 15-24 and 25+). This average proportion was then used in the above equation to calculate the number of individuals of each species killed during the breeding season by a goshawk pair. To get an estimate of the total number of each species killed each year by the entire goshawk population and how that has changed as the goshawk population increased in abundance, we multiplied our estimate of the number of individuals killed by a pair of goshawks (IK) by the average number of home-ranges occupied by goshawks for each of the goshawk abundance categories. The average number of homeranges occupied in each goshawk abundance category was estimated to be 6.5, 21.75 and 27.38 when 1-14, 15-24 and 25+ goshawk home-ranges were occupied respectively. 
Appendix 3: List of the species killed by northern goshawks in Kielder Forest, and the taxonomic prey group they were assigned to, along with the body mass used for each species to estimate their percentage biomass contribution to goshawk diet. We were not always able to differentiate between male and female prey remains, consequently we used the midpoint between the average mass for males and females in our biomass estimates. Body mass estimates for birds were obtained from the British Trust for Ornithology's website (www.bto.org/birdfacts) and mass estimates for mammals were obtained from the British Mammal Societies website (http://www.mammal.org.uk).

\begin{tabular}{clc}
\hline Prey group & Common name & Mass (g) \\
\hline Corvid & Carrion crow/rook (Corvus corone/C. frugilegus & 510 \\
Corvid & Eurasian jay (Garrulus glandarius) & 170 \\
Corvid & Jackdaw (Corvus monedula) & 220 \\
Corvid & Magpie (Pica pica) & 220 \\
Corvid & Raven (Corvus corax) & 1200 \\
\hline Game & Black grouse (Tetrao tetrix) & 1065 \\
Game & Pheasant (Phasianus colchicus) & 1190 \\
Game & Red grouse (Lagopus lagopus scotica) & 600 \\
Game & Red-legged partridge (Alectoris rufa) & 490 \\
\hline Mammal & Common shrew (Sorex araneus) & 9.5 \\
Mammal & European hare (Lepus europaeus) & 3500 \\
Mammal & European rabbit (Oryctolagus cuniculus) & 1600 \\
Mammal & Field vole (Microtus agrestis) & 30 \\
Mammal & Grey squirrel (Sciurus carolinensis) & 552.5 \\
Mammal & Mole (Talpa europaea) & 100 \\
Mammal & Pygmy shrew (Sorex minutus) & 4 \\
Mammal & Rat (Rattus norvegicus) & 360 \\
Mammal & Red squirrel (Sciurus vulgaris) & 200 \\
Mammal & Stoat (Mustela erminea) & 266.25 \\
Mammal & Weasel (Mustela nivalis) & 90.25 \\
\hline Other & Blackbird (Turdus merula) & 100 \\
Other & Black-headed gull (Chroicocephalus ridibundus) & 290 \\
Other & Blue tit (Cyanistes caeruleus) & 10.5 \\
Other & Budgerigar (Melopsittacus undulatus) & 35 \\
Other & Chaffinch (Fringilla coelebs) & 24 \\
Other & Coal tit (Periparus ater) & 9 \\
Other & Common frog (Rana temporaria) & 22.7 \\
Other & Common gull (Larus canus) & 400 \\
Other & Common lizard (Zootoca vivipara) & 4 \\
Other & Common toad (Bufo bufo) & 55 \\
Other & Crossbill (Loxia curvirostra) & 43 \\
Other & Cuckoo (Cuculus canorus) & 120 \\
Other & Curlew (Numenius arquata) & 985 \\
Other & Domestic chicken (Gallus gallus domesticus) & \\
Other & Eurasian bullfinch (Pyrrhula pyrrhula) & \\
Other & Fieldfare (Turdus pilaris) & \\
\hline & & \\
& & \\
\hline
\end{tabular}




\begin{tabular}{|c|c|c|}
\hline Prey group & Common name & Mass (g) \\
\hline Other & Goldcrest (Regulus regulus) & 6 \\
\hline Other & Great spotted woodpecker (Dendrocopos major) & 85 \\
\hline Other & Great tit (Parus major) & 18.5 \\
\hline Other & Green woodpecker (Picus viridis) & 190 \\
\hline Other & Kittiwake (Rissa tridactyla) & 410 \\
\hline Other & Lapwing (Vanellus vanellus) & 230 \\
\hline Other & Lesser black-backed gull (Larus fuscus) & 830 \\
\hline Other & Lesser redpoll (Acanthis cabaret) & 11 \\
\hline Other & Mallard (Anas platyrhynchos) & 1090 \\
\hline Other & Meadow pipit/tree pipit (Anthus pratensis/A. trivialis) & 19 \\
\hline Other & Mistle thrush (Turdus viscivorus) & 130 \\
\hline Other & Moorhen (Gallinula chloropus) & 320 \\
\hline Other & Newt (Triturus vulgaris) & 30 \\
\hline Other & Oyster catcher (Haematopus ostralegus) & 540 \\
\hline Other & Pied wagtail (Motacilla alba) & 21 \\
\hline Other & Redshank (Tringa totanus) & 120 \\
\hline Other & Robin (Erithacus rubecula) & 18 \\
\hline Other & Siskin (Spinus spinus) & 15 \\
\hline Other & Skylark (Alauda arvensis) & 38.5 \\
\hline Other & Snipe (Gallinago gallinago) & 110 \\
\hline Other & Song thrush (Turdus philomelos) & 83 \\
\hline Other & Starling (Sturnus vulgaris) & 78 \\
\hline Other & Swallow (Hirundo rustica) & 18.5 \\
\hline Other & Teal (Anas crecca) & 330 \\
\hline Other & Tree creeper (Certhia familiaris) & 10 \\
\hline Other & Whinchat (Saxicola rubetra) & 17 \\
\hline Other & Willow warbler (Phylloscopus trochilus) & 10 \\
\hline Other & Woodcock (Scolopax rusticola) & 280 \\
\hline Pigeon & Collared dove (Streptopelia decaocto) & 200 \\
\hline Pigeon & Feral pigeon (Columba livia) & 300 \\
\hline Pigeon & Wood pigeon (Columba palumbus) & 450 \\
\hline Raptor & Barn owl (Tyto alba) & 300 \\
\hline Raptor & Common buzzard (Buteo buteo) & 890 \\
\hline Raptor & Common kestrel (Falco tinnunculus) & 208 \\
\hline Raptor & Long-eared owl (Asio otus) & 290 \\
\hline Raptor & Merlin (Falco columbarius) & 205 \\
\hline Raptor & Northern goshawk (Accipiter gentilis) $\dagger$ & 1000 \\
\hline Raptor & Short-eared owl (Asio flammeus) & 330 \\
\hline Raptor & Sparrowhawk (Accipiter nisus) & 205 \\
\hline Raptor & Tawny owl (Strix aluco) & 470 \\
\hline
\end{tabular}

$\dagger$ Goshawk chicks were only included in the diet if there was evidence to suggest that it was a case of cannibalism rather than fledglings dying in the nest. 
Appendix 4: Variation in the proportion of northern goshawk diet made up different prey groups as goshawk abundance increased. Total refers to all dietary data collected during the breeding season between 1973 and 2014, the other columns show estimates from dietary data collected in years when 1-14, 15-24 and 25 or more goshawk home-ranges were occupied.

\begin{tabular}{|c|c|c|c|c|c|c|c|c|c|c|c|c|}
\hline \multirow[t]{2}{*}{ Prey group } & \multicolumn{4}{|c|}{$n$} & \multicolumn{4}{|c|}{ \% Biomass } & \multicolumn{4}{|c|}{ \% Frequency } \\
\hline & Total & $1-14$ & $15-24$ & $25+$ & Total & $1-14$ & $15-24$ & $25+$ & Total & $1-14$ & $15-24$ & $25+$ \\
\hline Pigeon (Columbidae) & 3724 & 1019 & 1601 & 1104 & 43.37 & 51.80 & 41.75 & 39.82 & 47.97 & 57.18 & 46.61 & 43.36 \\
\hline Corvid (Corvidae) & 1379 & 190 & 694 & 495 & 19.15 & 11.52 & 22.18 & 20.25 & 17.76 & 10.66 & 20.20 & 19.44 \\
\hline Game (Phasianidae, Tetraonidae) & 748 & 296 & 287 & 165 & 15.55 & 25.46 & 13.97 & 10.91 & 9.64 & 16.61 & 8.36 & 6.48 \\
\hline Mammal & 541 & 74 & 255 & 212 & 14.08 & 6.13 & 15.16 & 18.05 & 6.97 & 4.15 & 7.42 & 8.33 \\
\hline Raptor (Accipitridae, Falconidae, Strigidae) & 465 & 44 & 225 & 196 & 4.35 & 2.05 & 4.16 & 6.17 & 5.99 & 2.47 & 6.55 & 7.70 \\
\hline Other & 906 & 159 & 373 & 374 & 3.50 & 3.04 & 2.77 & 4.80 & 11.67 & 8.92 & 10.86 & 14.69 \\
\hline Total & 7763 & 1782 & 3435 & 2546 & 100 & 100 & 100 & 100 & 100 & 100 & 100 & 100 \\
\hline
\end{tabular}


Appendix 5: Occurrence of raptor species in the breeding season diet of a northern goshawk population in Kielder Forest, UK when the number of goshawk home-ranges occupied each year was estimated to be 1-14, 15-24 and 25 or more.

\begin{tabular}{|c|c|c|c|c|c|c|c|c|c|c|c|c|c|c|c|c|}
\hline \multirow[t]{2}{*}{ Species } & \multicolumn{4}{|c|}{$n$} & \multicolumn{4}{|c|}{$\%$ Biomass } & \multicolumn{4}{|c|}{ \% Frequency } & \multicolumn{4}{|c|}{$\%$ of raptors } \\
\hline & Total & $1-14$ & $15-24$ & $25+$ & Total & $1-14$ & $15-24$ & $25+$ & Total & $1-14$ & $15-24$ & $25+$ & Total & $1-14$ & $15-24$ & $>25$ \\
\hline Common kestrel * & 228 & 24 & 128 & 76 & 1.46 & 0.68 & 1.83 & 1.48 & 2.94 & 1.35 & 3.73 & 2.99 & 49.03 & 54.55 & 56.89 & 38.78 \\
\hline Tawny owl * & 106 & 7 & 30 & 69 & 1.53 & 0.45 & 0.97 & 3.04 & 1.37 & 0.39 & 0.87 & 2.71 & 22.80 & 15.91 & 13.33 & 35.20 \\
\hline Sparrowhawk & 48 & 2 & 22 & 24 & 0.30 & 0.06 & 0.31 & 0.46 & 0.62 & 0.11 & 0.64 & 0.94 & 10.32 & 4.55 & 9.78 & 12.24 \\
\hline Short-eared owl * & 23 & 7 & 14 & 2 & 0.23 & 0.32 & 0.32 & 0.06 & 0.30 & 0.39 & 0.41 & 0.08 & 4.95 & 15.91 & 6.22 & 1.02 \\
\hline Barn owl * & 14 & 0 & 3 & 11 & 0.13 & 0 & 0.06 & 0.31 & 0.18 & 0 & 0.09 & 0.43 & 3.01 & 0 & 1.33 & 5.61 \\
\hline Long-eared owl * & 17 & 0 & 12 & 5 & 0.15 & 0 & 0.24 & 0.14 & 0.22 & 0 & 0.35 & 0.20 & 3.66 & 0 & 5.33 & 2.55 \\
\hline Merlin & 14 & 0 & 12 & 2 & 0.09 & 0 & 0.17 & 0.04 & 0.18 & 0 & 0.35 & 0.08 & 3.01 & 0 & 5.33 & 1.02 \\
\hline Northern goshawk & 13 & 4 & 3 & 6 & 0.40 & 0.55 & 0.21 & 0.56 & 0.17 & 0.22 & 0.09 & 0.24 & 2.80 & 9.09 & 1.33 & 3.06 \\
\hline Common buzzard & 2 & 0 & 1 & 1 & 0.05 & 0 & 0.06 & 0.08 & 0.03 & 0 & 0.03 & 0.04 & 0.43 & 0 & 0.44 & 0.51 \\
\hline
\end{tabular}

* Denotes raptor species which are dependent on field voles. 
Appendix 6: The proportion of goshawk breeding attempts which were successful (i.e. fledged at least one chick) shown in relation to goshawk abundance (number of occupied goshawk territories) and according to when the goshawk home-range first became established. Numbers in parentheses are the total number of breeding attempts for each category.

\begin{tabular}{lccc}
\hline \multirow{2}{*}{$\begin{array}{c}\text { Home-ranges } \\
\text { established }\end{array}$} & \multicolumn{3}{c}{ Number of occupied goshawk home } \\
& $\leq 14$ & $15-24$ & $\geq 25$ \\
\cline { 2 - 4 } & $0.73(60)$ & $0.76(114)$ & $0.51(112)$ \\
Early (1973-1986) & - & $0.77(96)$ & $0.61(125)$ \\
Middle (1987-2001) & - & $0.75(20)$ & $0.25(44)$ \\
Late (2002-2014) & & & \\
\hline
\end{tabular}

